\title{
A retrospective study of perioperative outcomes following surgery for brain tumors: objective assessment and risk factor evaluation in rural centre
}

\author{
Sachidanand Gautam ${ }^{1}$, Ojha Piyush ${ }^{2}$, Sharma Anubhav ${ }^{3}$ \\ Government Medical College, Kota Rajasthan, INDIA \\ ${ }^{1}$ Neurosurgery, Associate Professor and Head Department of Neurosurgery \\ ${ }^{2}$ Neurology, Senior Resident, Department of Neurology, \\ ${ }^{3}$ Anesthesiology, Senior Resident, Department of Anesthesiology
}

\begin{abstract}
Background: Extensive surgical resection remains nowadays the best treatment available for most brain tumours. Perioperative outcomes following surgery for brain tumors are an important indicator of the safety as well as efficacy of surgical intervention. The goal of this study was to review the results of surgical treatment in our Department, run by a single neurosurgeon, in order to quantify morbidity and mortality and determine predictive risk factors for each patient. Materials and Methods: A total of Three hundred patients undergoing various surgeries for brain tumors were analyzed. Routine surgical techniques and uniform antibiotic policy were used. Navigation advanced operating microscope/ intraoperative electrophysiological monitoring was not available. The endpoints assessed included immediate postoperative neurological status, neurological outcome at discharge, regional complications, systemic complications, overall morbidity, and mortality. Various risk factors assessed included clinicoepidemiological factors, tumor-related factors, and surgery-related factors. Results: Median age was 36.37 years. $74.3 \%$ had tumors larger than $4 \mathrm{~cm}$. Neurological morbidity, and regional and systemic complications occurred in 14.3,14.3, and $11.3 \%$, respectively. Overall, major morbidity occurred in $14.3 \%$ and perioperative mortality rate was $3.3 \%$. Conclusions: Our patients were younger and had larger tumors than were generally reported. Despite the unavailability of advanced intraoperative aids, we could achieve acceptable levels of morbidity and mortality rates. The knowledge of the complications rate in each particular neurosurgical department turns out essentially to provide the patient with tailored information about risks before surgery.
\end{abstract}

Key words: Brain tumors, neurological outcomes, perioperative outcomes, surgical complications 


\section{Introduction}

Outcome assessment is an important part of evaluation of any form of therapy. Neurooncology has evolved into a specialty in its own right, with dedicated neuro-oncology services providing neurologically well preserved. The possible advantages of surgery have to be weighed against the comprehensive care for patients with brain tumors.[1] Surgery oftenly remains the primary form of treatment for various brain tumors. While on one side, there is unequivocal evidence of the survival benefit of radical resection of tumors[2-8], on the other hand it is important to preserve and possibly restore neurological function. In the current era, there has been an increase in the early detection of tumors due to advancement in imaging technology, especially at a stage when the patient may be potential risks involved,[2] which are often the limiting factor in radical surgery. Majority of the neurosurgeons today follow the principle of 'safe maximal resection'. Newer technology such as navigation, intraoperative imaging, and intraoperative monitoring helps neurosurgeons to achieve these goals. The goals, when dealing with the tumor, are twofold - a long-term goal of oncological control (reflected in the progression-free, disease-free, and overall survival); and the short-term goal of ensuring minimal therapyrelated toxicity (which in the context of surgery would translate into immediate Perioperative outcomes). As the option of surgery is very crucial in the control of CNS tumors (especially gliomas), systematic and objective documentation of Perioperative outcomes is important. Not only does it provide a baseline data for a centre, which can be very useful for patient counselling with regard to the risks of surgery (which may vary from centre to centre), but also allows a particular centre to objectively assess the benefits of introduction of new technology. Adding to that, it helps in comparison across various centres, especially when large multicentric trials are conducted, especially relevant for developing countries where resources are limited, with an aim to compensate cost-constrained infrastructure and at the same time providing satisfactory results. Our department, consisting of single neurosurgeon, is at the Government Medical college,Kota, Rajasthan, which is a tertiary care centre rendering medical services to a large population of south-east Rajasthan. This article is an attempt to objectively document the Perioperative outcomes after surgeries for different brain tumors.

\section{Materials and methods}

This observational study was conducted at the department of Neurosurgery at Government Medical College, Kota, Rajasthan. All the patients who underwent surgery for all types of brain tumors over a period of 4 years (2013 - 2017) were included. During surgeries, standard neurosurgical principles were followed. No intraoperative monitoring tools (navigation, microscope, intraoperative imaging, and intraoperative monitoring) were available during this time period. A uniform policy of antibiotic prophylaxis (single dose Perioperative second 
or third generation cephalosporin) was applied. All patients were operated under a Perioperative cover of manitol and corticosteroids (dexamethasone), which was tapered postoperatively. Antiepileptic medications were used in all patients perioperatively. Non-pharmacological deep venous thrombosis prophylaxis, in the form of intermittent pneumatic compression devices and thrombo-elastic devices (stockings) were utilized with pharmacological prophylaxis (heparin or low-molecular weight heparins) reserved for patients with anticipated prolonged recumbence.

The outcome measures assessed included immediate postoperative (first 24 hours) neurological status, neurological status at discharge, regional complications, systemic complications, overall morbidity, and Perioperative mortality. The neurological status at each time point was recorded as same, improved, or worse as compared to the immediate previous assessment. It was further categorized as per severity into minor (minimal alteration of function) or major (significant alteration in function), as well as in terms of duration, as transient (completely or significantly reversible by the time of discharge) or prolonged (minimal or no improvement till the time of discharge). Regional complications included the presence of significant operative site hematoma, worsening or new onset seizures, as well as wound-related complications (which included wound collection, gape, leak, and surgical site infection defined as per the Centres for Disease Control (CDC) criteria [9]). The systemic complications included all other complications such as metabolic disturbances, hemodynamic complications, systemic infections, and coagulopathy. The overall morbidity as well as mortality (at the time of discharge) was also recorded. For each of the endpoints mentioned various potential risk factors were assessed. These included preoperative predictors (clinicoepidemiological characteristics, such as, age, gender, preoperative neurological status, altered sensorium, KPS score, prior treatment history, comorbid illnesses), surgery-related variables (infra- or supratentorial, emergency surgery, duration of surgery [more than or less than four hours], head shaving, use of wound drain, and the extent of resection [subjectively based on surgeon's impression and postoperative CT scans]), as well as tumorrelated factors (size [single largest dimension more than or less than $4 \mathrm{~cm}$ ], location, and histology). This analysis was performed for the whole set of patients as well as for the subset of gliomas $(\mathrm{n}=152)$ as well as glioblastomas $(\mathrm{n}=$ 65).

For the purpose of statistical analysis, the risk factors were dichotomized as shown in Table 1. The endpoints were also dichotomized to denote the presence or absence of a particular complication. For neurological outcomes, improvements and no change were considered as favorable outcomes, whereas, worsening was considered as a complication for uni- and multivariate analysis.

\section{Results}

During the study period, a total of 300 surgeries were done for brain tumors. Mean age of all the patients was 36.37 years. Male: 
female ratio was 1.3:1(Table 1). Out of all the patients, 152 patients (50.6\%) had glial tumors while rest of the patients had non-glial tumors including embryonal tumors and metastasis (Table 2).The overall complications encountered are as summarized in Table 4. Two hundred and fifty-one patients (83.7\%) remained the same neurologically $(\mathrm{n}=84$ [28\%]) or had improved $(\mathrm{n}=167$ [55.7\%]) postoperatively. Of the 84 who remained the same, only six had improved further till the time of discharge and three had died due to other complications. On the other hand, of the 167 with immediate postoperative improvement, 53 further improved till discharge. Thus, neurological improvement was seen in the immediate postoperative period and was a dynamically sustained phenomenon in those that improved, evolving over the postoperative period. At the same time neurological worsening was encountered in $49(16.3 \%)$, of whom one-third $(n=16)$ had minor deficits (all being transient except one) and two-thirds $(\mathrm{n}=33)$ suffered major deficits (only six improved till discharge). Comparing the postoperative neurological outcomes with the preoperative neurological status revealed that of the 52 (17.6\%) preoperative, neurologically normal patients, ninteen $(6.1 \%)$ experienced postoperative worsening (6 being minor deficits, 3 of which were transient, and 10 were major, of which two were transient). There was no mortality in this group. Of the 248 (82.6\%) patients with preoperative neurological deficits, 98 (32.6\%) remained the same, 110 (36.6\%) had improved, whereas, 30 (10\%) worsened. All ten patients who died were from this subgroup.

Regional complications were encountered in $14.3 \%$ patients [Table 4 ]. Of these, wound- related complications were the major contributors (10.6\%), with surgical site infections predominating (6.6\%). Systemic complications occurred in $11.3 \%$, the majority being metabolic disturbances (hyponatremia commonly), most of which were reversible. Clinically significant coagulopathy occurred in only $2 \%$.

Although neurological worsening (16.3\%) was an important contributor to the overall morbidity (39.9\%), it is evident from Table 6 that other postoperative complications (regional and systemic) were significant contributors (if not more) to the overall outcomes. In fact $22.6 \%$ of those with no neurological morbidity sustained some other form of morbidity in the postoperative period [Table 4].

The average duration of postoperative stay was 9.2 days (7.2 days for those with no morbidity and 12.4 days for those with some postoperative complication).Ten patients died in the postoperative period. The details of the cause of death are depicted in Table 5.

Various risk factors were analyzed for each complication [Table 3]. All the possible factors were initially tested in a univariate analysis [Table 3].On univariate analysis none of the risk factors were significant for immediate postoperative neurological status or regional complications. Patients with preoperative neurological deficits and those undergoing emergency surgery were more likely to have systemic complications. Age less than 18 years and emergency surgery were predictive of increased morbidity and mortality. In addition, the presence of preoperative altered sensorium was predictive of higher perioperative mortality. 

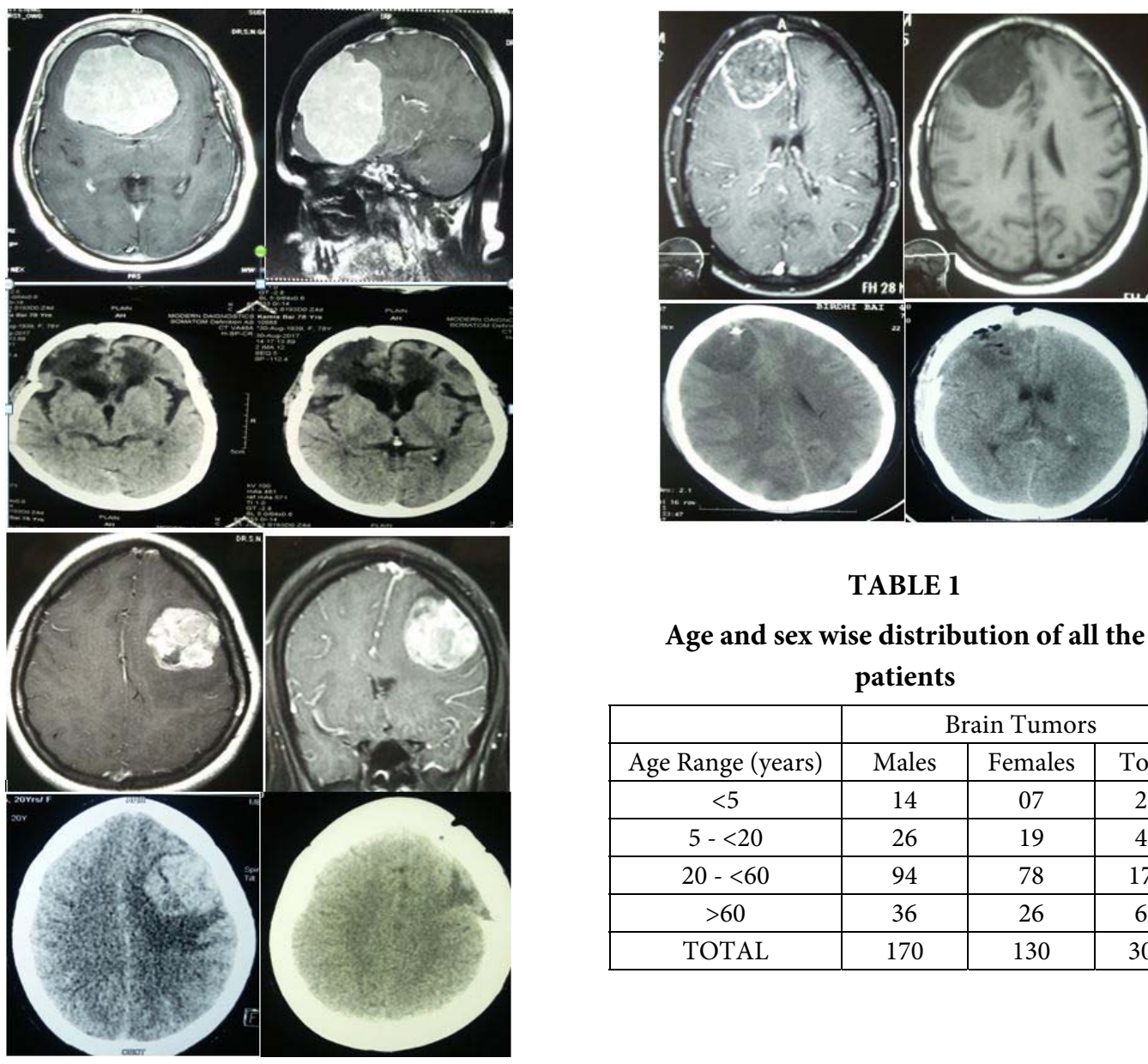

TABLE 1

Age and sex wise distribution of all the patients

\begin{tabular}{|c|c|c|c|}
\hline & \multicolumn{3}{|c|}{ Brain Tumors } \\
\hline Age Range (years) & Males & Females & Total \\
\hline$<5$ & 14 & 07 & 21 \\
\hline $5-<20$ & 26 & 19 & 45 \\
\hline $20-<60$ & 94 & 78 & 172 \\
\hline$>60$ & 36 & 26 & 62 \\
\hline TOTAL & 170 & 130 & 300 \\
\hline
\end{tabular}

\section{TABLE 2}

Histological spectrum of cases

\begin{tabular}{llll} 
& & Numbers & Total \\
Glial tumors & Astrocytic tumors & 96 & $152(50.7 \%)$ \\
& Oligodendroglial tumors & 16 & \\
Ependymal tumors & 17 & \\
Medulloblastoma & 23 & \\
Non-glial tumors & Metastases & 13 & \multirow{2}{*}{$148(49.3 \%)$} \\
& Embryonal tumors & 12 & \\
& Meningioma & 53 & \\
Schwannoma & 21 &
\end{tabular}


TABLE 3

Demographic, clinical, surgical, and tumours type profile

\begin{tabular}{|c|c|c|c|}
\hline & & Number & Percent \\
\hline \multicolumn{4}{|l|}{ Demographic profile } \\
\hline Age & Median age (range) & \multicolumn{2}{|c|}{36.37 years } \\
\hline Gender & Male / female & $170 / 130$ & $56.6 / 43.3$ \\
\hline \multicolumn{4}{|l|}{ Clinical features } \\
\hline Pre-op. Neurological deficits & Yes / No & $248 / 52$ & $82.7 / 17.3$ \\
\hline Pre-op. altered sensorium & Yes / No & $62 / 238$ & $20.6 / 79.4$ \\
\hline \multirow[t]{2}{*}{ KPS(Karnofsky Performance Scale) } & Median KPS & 80 & \\
\hline & $\leq 70 />70$ & $160 / 140$ & $53.2 / 46.8$ \\
\hline Prior treatment & Yes / No & $04 / 296$ & $1.3 / 98.7$ \\
\hline \multicolumn{4}{|l|}{ Surgical features } \\
\hline Nature & Emergency / elective & $31 / 269$ & $10.3 / 89.7$ \\
\hline Site & Infratentorial / Supratentorial & $117 / 183$ & $38.9 / 61.1$ \\
\hline \multirow[t]{2}{*}{ Duration of surgery } & Mean & \multicolumn{2}{|c|}{4.1 hours } \\
\hline & $>3$ hours $/ \leq 3$ hours & $136 / 164$ & $45.4 / 54.6$ \\
\hline Extent of resection & Gross total / subtotal & $219 / 81$ & $72.9 / 27.1$ \\
\hline \multicolumn{4}{|l|}{ Tumor-related features } \\
\hline Tumor size & $>4 \mathrm{~cm} / \leq 4 \mathrm{~cm}$ & $223 / 77$ & $74.3 / 25.7$ \\
\hline Histology & Glioma / others & $152 / 148$ & $50.7 / 49.3$ \\
\hline
\end{tabular}

\section{TABLE 4}

Postoperative complications

\begin{tabular}{lcc} 
Complications & Number & Percent \\
\hline Neurological worsening (overall) & 49 & 16.3 \\
& 16 & 5.3 \\
Minor & & \\
& 33 & 11 \\
Major & & \\
& 43 & 14.3 \\
Regional complications (overall) & & \\
& & 6.6 \\
Wound-related & 20 & 2 \\
Wound leak & 6 & 2 \\
Wound gape & 6 &
\end{tabular}




\begin{tabular}{lcc} 
Meningitis & 3 & 1 \\
Other (collection, & 6 & 2 \\
pseudomeningoceles) & & \\
& & \\
Significant operative site & 13 & 4.3 \\
Hematoma & & 3 \\
New / increased seizures & 9 & 11.3 \\
Systemic complications (overall) & 34 & 2 \\
Coagulopathy & 6 & 2 \\
Hemodynamic & 6 & 7.3 \\
Metabolic & 22 & 11.3 \\
Other complications & 34 & \\
& & 0.6 \\
Re-exploration & 02 & \\
& & 37.3 \\
Morbidity (overall) & 112 & 3.3 \\
Minor & 69 & \\
Major & 43 & \\
& & \\
Mortality & 10 & \\
\hline
\end{tabular}

\section{TABLE 5}

Details of perioperative mortality

Clinical details
74/ M, presented with focal
deficits
16 / M with raised ICP
30 / M with ataxia
1 / M with altered sensorium
8 / M with ataxia
39 / F in altered sensorium
28 / M altered sensorium
$24 / F$ with raised ICP
38/F with ataxia
70/M altered sensorium

Tumor

Bifrontal GBM

Recurrent Craniopharyngioma

$\mathrm{CP}$ angle Schwanoma

Posterior fossa Medulloblasoma

Medulloblastoma

Metastasis from adenocarcinoma

Large petroclival meningioma

Large left parasagital meningioma

Posterior fossa meningioma

Metastasis from adenocarcinoma
Postoperative events

Postoperative metabolic and multisystem failure

Metabolic disturbance

Post-operative thrombocytopenia with hematoma

Brainstem dysfunction with aspiration Hydrocephalus and coning

Progressive coning

Progressive coning

Progressive coning

Brainstem dysfunction with aspiration Postoperative metabolic and multisystem failure 
TABLE 6

Comparative analysis of patient characteristics and perioperative outcomes in selected series of intraaxial tumors

\begin{tabular}{|c|c|c|c|c|c|c|c|c|c|c|}
\hline & \multirow[b]{2}{*}{ Sawaya ${ }^{10}$, } & \multirow[b]{2}{*}{$\begin{array}{c}\text { Brell }^{11} \\
2000\end{array}$} & \multicolumn{2}{|c|}{$\begin{array}{l}\text { GOP study }{ }^{17}, 2005 \\
\text { (multicentric) }\end{array}$} & \multirow[b]{2}{*}{$\begin{array}{c}\text { Rabadan }^{13}, \\
2007\end{array}$} & \multicolumn{3}{|c|}{ Moiyadi $^{16} 2010$} & \multirow{2}{*}{$\begin{array}{c}\text { Present } \\
\text { Study, } \\
2017 \\
\text { All }\end{array}$} \\
\hline & & & & Primary & Recurrent & & $\begin{array}{l}\text { All } \\
\text { intra- } \\
\text { axial }\end{array}$ & Gliomas & GBM & \\
\hline \multicolumn{2}{|c|}{ Number cases (years) } & $\begin{array}{c}400 \\
(2 \text { years })\end{array}$ & $\begin{array}{c}200 \\
\text { (6 years) }\end{array}$ & 408 & 91 & $\begin{array}{c}236 \\
\text { (6 years) }\end{array}$ & $\begin{array}{c}196 \\
(3 \\
\text { years })\end{array}$ & 130 & 65 & $\begin{array}{c}300 \\
(4 \text { years })\end{array}$ \\
\hline \multicolumn{2}{|c|}{$\begin{array}{l}\text { Histology (gliomas / } \\
\text { mets / } \\
\text { others) }\end{array}$} & $\begin{array}{c}206 / 194 \\
/ 0\end{array}$ & $\mid \begin{array}{c}166 / 34 / \\
0\end{array}$ & $408 / 0 / 0$ & $91 / 0 / 0$ & $168 / 65 / 3$ & $\begin{array}{c}130 / \\
38 / 28\end{array}$ & - & - & $152 / 13 / 49$ \\
\hline \multicolumn{2}{|c|}{$\begin{array}{l}\text { Site (supra / } \\
\text { infratentorial) }\end{array}$} & $358 / 42$ & $181 / 19$ & - & - & $220 / 16$ & $166 / 30$ & - & - & $183 / 117$ \\
\hline \multicolumn{2}{|l|}{ Median age } & 48 & $\begin{array}{c}51.7 \\
\text { (mean) }\end{array}$ & 55 & 50 & 51 & 38 & 38 & & 36.37 \\
\hline \multicolumn{2}{|l|}{ Median KPS } & 80 & - & 90 & 80 & $\begin{array}{l}\text { (selected only } \\
\text { those }>60)\end{array}$ & 80 & & & $\begin{array}{l}80 \\
- \\
-\end{array}$ \\
\hline \multicolumn{2}{|c|}{ Prior treatment (\%) } & 38 & - & - & 100 & - & 31.6 & & & 1.3 \\
\hline \multicolumn{2}{|c|}{$\mathrm{T}$ size $>4 \mathrm{~cm}(\%)$} & - & - & 56 & 55 & - & 71.9 & & & 74.3 \\
\hline \multicolumn{2}{|c|}{$\begin{array}{l}\text { Gross total (> 90\%) } \\
\text { resection (\%) }\end{array}$} & 73 & 66 & 56 & 54 & 64 & 71.4 & & & 72.9 \\
\hline \multirow[b]{2}{*}{$\begin{array}{l}\text { Morbidity } \\
(\%)\end{array}$} & Overall & 32 & - & 24.2 & 32.6 & 18.9 & 38.8 & 32.3 & 37 & 39.9 \\
\hline & Major & 13 & 27.5 & - & - & - & 17.9 & 17.8 & 21.5 & 14.3 \\
\hline \multirow[b]{2}{*}{$\begin{array}{l}\text { Neurological } \\
\text { outcome (\%) } \\
\end{array}$} & Worsening & $\begin{array}{l}10(8.5 \\
\text { major })\end{array}$ & $\begin{array}{c}20.5 \\
\text { (all major) } \\
18.5 \% \text { KPS } \\
\text { worsening }\end{array}$ & 8 & 18 & $\begin{array}{c}14.5 \\
\text { (11.5 major) } \\
8 \% \text { KPS } \\
\text { worsening } \\
\end{array}$ & $\begin{array}{c}16.8 \\
(11.2 \\
\text { major })\end{array}$ & $\begin{array}{c}17 \\
(12.3 \\
\text { major })\end{array}$ & $\begin{array}{c}20 \\
(17 \\
\text { major })\end{array}$ & 16.3 \\
\hline & $\begin{array}{l}\text { Same / } \\
\text { improved }\end{array}$ & 90 & & 92 & 82 & & 83.2 & 83 & 80 & $\begin{array}{c}83.7 \\
- \\
\end{array}$ \\
\hline \multicolumn{2}{|l|}{ Regional (\%) } & 7 & 16 (major) & 10 & 13 & $\begin{array}{c}\text { Combined } \\
\text { with } \\
\text { neurological } \\
\text { outcome }\end{array}$ & $\begin{array}{l}17.3 \\
\text { (all) }\end{array}$ & 18 & 27 & 14.3 \\
\hline \multicolumn{2}{|l|}{ Systemic (\%) } & 7.7 & $\begin{array}{c}4.5 \\
\text { (major) }\end{array}$ & 9.2 & 8.7 & 4.5 & 10.7 & 11.5 & 14 & 11.3 \\
\hline \multicolumn{2}{|l|}{ Mortality (\%) } & 1.7 & 2.5 & 1.5 & 2.2 & 2.9 & 3.6 & 2.3 & 1.5 & 3.3 \\
\hline
\end{tabular}




\section{Discussion}

Perioperative outcomes are a measure of the short-term efficacy (neurological improvement and symptomatic relief) as well as the toxicity (perioperative morbidity and mortality) of a surgical intervention. With the use of multimodality therapy in the management of brain tumors it is very important to not only separate tumor-related and treatment-related effects, but also to identify the contributions of various treatment modalities toward treatment-related effects. For example neurological deficits (especially cognitive) in patients with supratentorial malignant gliomas could be due to the tumor itself, or as a result of surgery, or a consequence of radiotherapy. Appropriate evaluation at various relevant time points (including baseline) is essential. Moreover, this evaluation needs to be objective and uniformly reproducible.

Early neurosurgeons were more concerned with saving lives and the focus was more on mortality reduction. With refinements in technique and advances in adjuncts, reduction in morbidity started being discussed. Since then, numerous studies have been published for intra-axial tumors.[10-13] There are, however, certain limitations that we would like to discuss.

Study populations have been heterogeneous. Not only the clinical profile, but the tumor characteristics of apparently similar populations can be different [Table 6]. Our patients were significantly younger than those reported. Moreover, we had a much larger proportion of patients with big tumors. This we feel is probably because of the referral pattern at our centre, which drains a very large geographical region including remote and underserved areas, resulting in a significant time lag from the onset of symptoms to access to the necessary facilities and expertise. Although the influence of the preoperative tumor size on long-term outcomes is questionable, there is no doubt that larger tumors present a greater challenge during surgery and can adversely influence the perioperative outcomes. Moreover, it is likely that patients with larger tumors have raised intracranial pressure and altered neurological status, which was our experience too. Although the preoperative neurological status was a significant risk factor for overall morbidity and mortality on univariate analysis. This could be due to the small size of our series.

Another problem in comparing with literature is the lack of uniformity in reporting risk factors and end-points. Most studies report the karnofsky performance scale (KPS) as a surrogate marker of clinical status. The KPS, although an objective assessment tool, has significant limitations. It may not reflect all the neurological deficits accurately and may often underestimate the neurological morbidity. Few of the studies have reported neurological worsening, but others have reported only changes in KPS. A small but definite and measurable neurological worsening may not reflect in the KPS. Others have used more specific neurological outcome scales such as the NIH Stroke Score.[14] 
Nonetheless a scoring system, even as it ensures uniformity in measurement, tends to group outcomes and ignores small (but often clinically significant) differences. On the other hand the recording of individual neurological deficits may overestimate the neurological outcomes (both improvements as well as worsening). This (along with a more detailed reporting of regional complications in our series) may be a reason for the slightly increased overall morbidity we experienced.

For documenting surgical site infection, we rigorously followed the CDC guidelines as part of a parallel prospective study, documenting wound infections in our service. Nonetheless, the major morbidity in our series still compared favorably [Table 6]. We believe that the neurological status more accurately reflected the patients' clinical status and by meticulously documenting the status we were able to observe the temporal course of these deficits. Our results showed that neurological worsening (new deficits in $6.1 \%$ and aggravation of the existing deficits in 30\%) was a significant issue; however, most of these deficits resolved by the time of discharge. This information was very crucial while counseling and preparing patients for surgery. Moreover, neurosurgeons should be cognizant of the fact that non-neurological morbidity was also a significant cause of postoperative complications. Another important consideration was the resources available at various treating centers. Most reports were from western and developed nations, with access to the latest adjuncts and fewer cost constraints. During the period of the present analysis, we did not have navigation or intraoperative monitoring available. This was often the case with most resource-constrained centers in developing countries. Even as technological adjuncts definitely increased the surgeon's comfort level during surgeries and possibly allowed more extensive resections to be performed safely, their role in objectively improving the perioperative outcomes remains debatable.[15] Our results showed that even without the use of such aids, acceptable outcomes could be achieved. Being a single center, single surgeon service allowed us to have a uniform perioperative management policy, along with a meticulously maintained, prospective, database-ensured, reliable data capture. However, sustained and regular documentation of such seemingly mundane data was crucial to generalize these results across similar centers across the world.

\section{Limitations of our study:}

Postoperative MR imaging for documenting residual disease was not always logistically possible, thus limiting objective volumetric assessment in all cases. Moreover, although we did attempt to assess individual risk factors, the relatively small size of our study group may not have accurately reflected the true association precluding the statistically significant results.

\section{Correspondence}

Dr. S.N. Gautam

House no 63, Shrinathpuram, Sector B

Kota, Rajasthan-324010

India

+91-9413553530

\section{References}


1.Black P, Golby A, Johnson M. The Emerging Field of Neurosurgical oncology: Novel techniques to optimize outcomes and minimize mishaps. ClinNeurosurg 2007;54:36-46.

2.Sanai N, Berger MS. Glioma extent of resection and its impact on patient outcome. Neurosurgery 2008;62:75364; discussion 264-6.

3.Packer RJ, Vezina G. Management of and prognosis with medulloblastoma: Therapy at a crossroads. Arch Neurol 2008;65:1419-24.

4.Kalkanis SN, Kondziolka D, Gaspar LE, Burri SH, Asher AL, Cobbs CS, et al. The role of surgical resection in the management of newly diagnosed brain metastases: A systematic review and evidence-based clinical practice guideline. J Neurooncol 2010;96:33-43.

5.Pang BC, Wan WH, Lee CK, Khu KJ, Ng WH. The role of surgery in high-grade glioma--is surgical resection justified? A review of the current knowledge. Ann Acad Med Singapore 2007;36:358-63.

6.Sawaya R. Extent of resection in malignant gliomas: A critical summary. J Neurooncol 1999;42:303-5.

7.Ryken TC, Frankel B, Julien T, Olson JJ. Surgical management of newly diagnosed glioblastoma in adults: Role of cytoreductive surgery. J Neurooncol 2008;89:27186.

8.Moiyadi AV. Surgical management of malignant gliomas - Challenges and strategies. Int J NeurolNeurosurg 2009;1:21-7.

9.Mangram AJ. Hospital infection control practices advisory Committee (HICPAC) and Centers for Disease Control and Prevention (CDC). Guidelines for prevention of surgical site infection. Infect Control Hosp Epidemiol 1999;24:247-78.

10.Sawaya R, Hammoud M, Schoppa D, Hess KR, Wu SZ, Shi WM, et al. Neurosurgical outcomes in a modern series of 400 craniotomies for treatment of parenchymal tumors. Neurosurgery 1998;42:1044-55.
11.Brell M, Ibáñez J, Caral L, Ferrer E. Factors influencing surgical complications of intra-axial brain tumours. Acta Neurochir (Wien) 2000;142:739-50.

12.Chang SM, Parney IF, McDermott M, Barker FG 2nd, Schmidt $\mathrm{MH}$, Huang $\mathrm{W}$, et al. Perioperative complications and neurological outcomes of first and second craniotomies among patients enrolled in the Glioma Outcome Project. J Neurosurg 2003;98:1175-81. 13.Rabadán AT, Hernandez D, Eleta M, Pietrani M, Baccanelli M, Christiansen S, et al. Factors related to surgical complications and their impact on the functional status in 236 open surgeries for malignant tumors in a Latino-American hospital. SurgNeurol 2007;68:412-20; discussion 420 .

14.Stummer W, Pichlmeier U, Meinel T, Wiestler OD, Zanella F, Reulen HJ. ALA-Glioma Study Group. Fluorescence-guided surgery with 5 -aminolevulinic acid for resection of malignant glioma: A randomised controlled multicenter phase III trial. Lancet Oncol 2006;7:392-401.

15.Choudhari KA. Commentary: Surgery for glioblastoma and influence of technology on outcomes between developed and developing parts of the world. SurgNeurol 2010; 73(2): e16.

16.Moiyadi AV, Shetty PM. Perioperative outcomesfollowing surgery for brain tumors: Objective assessment and risk factor evaluation. J Neurosci Rural Pract 2012;3:28-35.

17.Silvia Scoccianti MD,et all; Patterns of Care and Survival in a Retrospective Analysis of 1059 Patients With Glioblastoma Multiforme Treated Between 2002 and 2007: A Multicenter Study by the Central Nervous System Study Group of Airo (Italian Association of Radiation Oncology) Neurosurgery, Volume 67, Issue 2, 1 August 2010, Pages 446-45. 